\title{
International Outsourcing in a Two-Sector Heckscher-Ohlin Model
}

\author{
Hartmut Egger \\ University of Zurich
}

\begin{abstract}
This paper analyzes the distributional effects of international outsourcing in a two sector Heckscher-Ohlin type model if both sectors get economical access to cost-saving international outsourcing. Thereby, it is shown that if both sectors are engaged in international outsourcing in equilibrium, the cost-saving effects of outsourcing as well as the factor contents of the outsourced fragments are relevant for the factor price effects. Concerning the Pareto-criterion the main finding is that a Pareto-improving factor price impact of international outsourcing cannot be excluded from a theoretical point of view.
\end{abstract}

- JEL Classification: F14, F15, F16, F40

- Key Words: International Outsourcing, General Equilibrium Analysis, Distributional Effects, Welfare Effects

\section{Introduction}

In the public and political discussion of industrialized economies opponents of globalization typically argue that globalization increases inequality. The fear is that firms try to exploit international factor price differences across economies by outsourcing (low-skilled) labor intensive parts of the value added chain to foreign. The conclusion is that a substitution of expensive home-supplied (low-skilled) labor by cheap foreign factors improves the income of capital owners at the cost of (low-skilled) labor. In contrast, proponents of globalization argue that the gains from the more efficient allocation of resources are so large that winners could fully

*Corresponding address: Hartmut Egger, University of Zurich, Department of Economics, Ramistrasse 62, CH-8001 Zurich, Switzerland. Tel: +41-1-63-42303, E-mail: egger@wwi.unizh.ch.

(c)2002-Center for International Economics, Sejong Institution, All Rights Reserved. 
compensate losers.

In the last decade the question of the distributional effects of international outsourcing has also reached the scientific discussion of economists. Jones (2000) and Jones and Kierzkowski $(1990,2001)$ have argued that technological changes have decreased the costs for service links required for coordination and communication activities, implying an intensified fragmentation of production processes. In particular, they stress that besides tariffs and legal non-tariff barriers such technological changes may account for the observed increase in international specialization. ${ }^{1}$ However, starting with Krugman (1995) international outsourcing is nowadays debated as alternative candidate to skill-biased technological change for explaining the increasing wage gap observed in the United States. Compare Feenstra and Hanson (1996a, 1996b) and Slaughter (2000) for empirical assessments. Using a wide measure of outsourcing including "all imported intermediate and final goods that are used of, or sold under the brandname of, an American firm” (p. 107) Feenstra and Hanson estimate a significant and large effect of the increase in international outsourcing on the U.S. wage differential in favor of high-skilled workers. In contrast, Slaughter does not find any large impact of international outsourcing in his examination of multinational enterprises head-quartered in the USA.

In the theoretical discussion Arndt $(1997,1999)$ challenged the conclusion which may be drawn from the theoretical discussion in Feenstra and Hanson (1996a, 1997), namely that international outsourcing by substituting the relative scarce factor of an economy depresses demand for the scarce factor. According to the analysis of Arndt, the factor price implications of international outsourcing critically depend on the input characteristics of the sector in which international outsourcing takes place. If the labor intensive sector gets via international outsourcing access to cheap labor abroad it is labor which gains relative to capital. The intuition behind this result is the following. Access to cheap factors abroad makes firms in the capital intensive sector more competitive so that they expand production. According to Arndt, the positive employment effect resulting from the expansion in production outweighs the negative effect of substituting home labor by foreign labor. ${ }^{2}$ Since it turns out that under diversification the impact of international outsourcing on factor prices is independent of the factor intensity of

\footnotetext{
${ }^{1}$ According to Kohler (2001b), "[t] his new pattern of specialization is perhaps best characterized as being driven by worldwide arbitrage operating (...) on ever smaller slices of the value added chain" ( $\mathrm{p}$. 2).

${ }^{2}$ However, as Egger and Egger (2001) have shown the result that labor gains relative to capital is not generally valid but critically depends on special assumptions which have to be assessed empirically.
} 
the imported intermediate good, and solely determined by the factor intensity of the sector which is engaged in outsourcing activities relative to the other sector, the impact of international outsourcing is said to be sector-biased, in contrast to the factor-biased impact predicted by in Feenstra and Hanson $(1996,1997){ }^{3}$ In a more general framework Jones (2000) and Jones and Kierzkowski (2001) analyze a number of possible factor price effects of international outsourcing. Venables (1999) shows that even in a two-sector model the distributional effects of international outsourcing are ambiguous, stressing thereby that "it is possible to generate some curious cases" (p. 943).

The issue of international outsourcing and factor price equalization is discussed in Deardorff (2001a, 2001b). Thereby, Deardorff (2001a) stresses that international fragmentation (of the value-added chain) "enhances the possibility of factor price equalization“" (p. 133f.), whereas Deardorff (2001b) argues that if fragmentation does not equalize factor prices across countries, it is not necessarily the case that factor prices move closer together.

Concerning the welfare effects of international outsourcing the analysis in Heckscher-Ohlin type models identifies a welfare gain which allows for redistributional measures to compensate the losers of outsourcing. Kohler (2001a) has questioned the generality of this result by showing that in a specific factors Ricardo-Viner framework, fixed costs of international outsourcing may yield a welfare decline in the home country.

In this paper I extend the literature building on two sector Heckscher-Ohlin type models with two (types of) primary factors in use by assuming that international outsourcing simultaneously occurs in both sectors. Following the formal analysis in Egger and Falkinger (2001) I argue that international outsourcing provides economical access to a new production technology which not only uses homesupplied inputs but also an imported intermediate good. Thus, by substituting foreign for home factors, international outsourcing may alter (at given factor

\footnotetext{
${ }^{3}$ Neither Arndt $(1997,1999)$ nor Feenstra and Hanson (1996a, 1996b) use the terms factor bias and sector bias. Kohler (2001a) introduced these terms into the discussion of international outsourcing. In the literature the discussion on whether it is the factor bias or the sector bias which matters is not new but well-known from the discussion of the channels through which technological progress affects the income distribution of an economy. According to Feenstra and Hanson (1999), this debate has resulted in an "apparent conflict in the literature" (p. 908). Whereas Leamer (1998) argues that the sector bias is relevant in a small open economy, Krugman (2000) points out that in a closed or large open economy it is the factor bias which matters.
} 
prices) the optimal factor intensity of primary inputs in the production process. ${ }^{4}$ In contrast to Egger and Falkinger (2001) and similar to Arndt (1997a, 1997b) I focus on diversified equilibria.

Although the analysis of international outsourcing is similar to the analysis of technological change, there are two main differences. First, as already mentioned above, international outsourcing means access to a set of inputs which is different from that in the absence of outsourcing. This point is made clear in the analysis by allowing for four technologies in the non-outsourcing situation. Firms of both sectors may in the absence of outsourcing opportunities choose between an integrated and a fragmented mode of production. If international outsourcing becomes economically attractive, firms can additionally decide to use intermediate goods produced in home or imported from abroad in the fragmented production process. Second, whereas technological change normally shifts at given input prices optimal factor intensities (either only in one sector or) in both sectors in the same direction, international outsourcing may substitute different factors in the two production sectors, implying that (at given factor prices) optimal factor intensities of the two sectors can move in opposite directions. Thus, access to international outsourcing can alter the ranking of sectors according to their factor intensities also in the case of diversification equilibria. ${ }^{5}$

Concerning the Pareto-criterion, the analysis in this paper confirms the view that economical access to cost-saving international outsourcing in a Heckscher-Ohlin type model exhibits a potential for a Pareto-improvement by redistributional measures of the government, i.e. winners gain more than losers lose. This is a direct consequence of the more efficient allocation of resources implied by international outsourcing. However, in contrast to the literature restricted on outsourcing in one sector, it is shown that international outsourcing may yield a Pareto-improvement (without any redistribution) in the home country if non-outsourcing technologies are totally substituted by outsourcing ones and the cost-saving effect of international outsourcing (at given factor prices) in the two sectors is not too different.

${ }^{4}$ Seeing outsourcing in this way is in line with the literature. Compare for instance Feenstra and Hanson (1999). Feenstra (1998) stresses that "outsourcing has a qualitatively similar effect on reducing the demand for unskilled relative to skilled labor within an industry as does skill-biased technological change" (p. 41). Throughout the paper I distinguish between non-outsourcing technologies (production modes in the absence of outsourcing) and outsourcing technologies (production modes if foreign resources are used via international outsourcing).

${ }^{5}$ Egger and Falkinger (2001) have shown that, if only one sector gets access to outsourcing opportunities, a change in the ranking of sectors according to their factor intensities is inconsistent with a diversified outsourcing equilibrium. 
Concerning the theoretical analysis and the graphical tools, I prefer the dual approach with a diagrammatic representation of unit isocost curves in the factor price space instead of the Lerner-Pearce diagram. This approach is motivated by Mussa (1979) who stated that this "diagrammatic technique (...) is particularly useful in illustrating the properties of the two sector model which are essentially concerned with prices" (p. 525). ${ }^{6}$

Section II characterizes the basic model. Section III determines the diversified non-outsourcing and outsourcing equilibria. Section IV identifies the distributional effects of international outsourcing and section V deals with the Pareto-criterion in the context of outsourcing. After some extensions in section VI, section VII summarizes the main findings.

\section{Model Characterization}

Consider a small open economy in which production is diversified on two sectors, that produce output $X^{1}$ and $X^{2}$ by employing two primary factors $K$ and L. All markets are perfectly competitive and primary factors are mobile across sectors but internationally immobile. The factor endowments of the economy are constant and given by $\bar{K}$ and $\bar{L}$. I assume that firms in both sectors have technological access to an integrated and a fragmented mode of production and that all production functions are linearly homogenous with strictly increasing and strictly quasiconcave unit cost functions.

\section{A. Non-Outsourcing Technologies}

Output in sector $i=1,2$ is produced subject to technology

$$
X^{i}=F^{i}\left(K_{i}^{f}, L_{i}^{f}\right)
$$

if firms in sector $i$ make use of the integrated production mode. If in contrast, the fragmented mode of production is in use the production of output $X^{i}$ is subject to a production function of the form ${ }^{7}$

\footnotetext{
${ }^{6}$ Feenstra and Hanson (1999) used the dual approach in their discussion on the impact of technologies on factor prices. However, in the literature on international outsourcing in the Heckscher-Ohlin model the Lerner Pearce diagram is the standard graphical tool for analyzing the distributional consequences of a splitting up of the value added chain.

${ }^{7}$ Note that I do not distinguish between national outsourcing and fragmentation within firms. (Compare for a formal distinction Egger and Falkinger, 2001). Therefore, fragmented production can also be associated with national outsourcing (in contrast to international outsourcing discussed below).
} 


$$
X^{i}=G^{i}\left(G_{i}^{1}\left(K_{i}^{g 1}, L_{i}^{g 1}\right), G_{i}^{2}\left(K_{i}^{g 2}, L_{i}^{g 2}\right)\right)
$$

$G_{i}^{1}$ and $G_{i}^{2}$ are the amounts of two fragments entering the production of commodity $X^{i}$. $G^{i}$ describes the assembling technology. Let

$$
c_{i}^{f}\left(w_{K}, w_{L}\right) \equiv w_{K} k_{i}^{f}\left(w_{K}, w_{L}\right)+w_{L} l_{i}^{f}\left(w_{K}, w_{L}\right)
$$

be the minimal unit costs of production for firms in sector $i$, which produce in an integrated way, according to (1). $k_{i}^{f} \equiv K_{i}^{f} / X^{i}$ and $l_{i}^{f} \equiv L_{i}^{f} / X^{i}$ are cost-minimal input coefficients of the integrated production mode. $w_{K}$ and $w_{L}$ denote prices of the two factors $K$ and $L$. Accordingly, let

$$
c_{i}^{g}\left(w_{K}, w_{L}\right) \equiv w_{K} k_{i}^{g}\left(w_{K}, w_{L}\right)+w_{L} l_{i}^{g}\left(w_{K}, w_{L}\right)
$$

be the minimal unit costs of fragmented production in sector $i$. Thereby, $k_{i}^{g} \equiv\left(K_{i}^{g 1}+X_{i}^{g 2}\right) / X^{i}$ and $l_{i}^{g} \equiv\left(L_{i}^{g 1}+L_{i}^{g 2}\right) / X^{i}$ are cost-minimal input coefficients of the fragmented production mode.

\section{B. Outsourcing Technology}

To preclude that one industry leaves the home country altogether, I assume that the foreign economy has neither access to the technology for producing intermediate good $G_{i}^{1}$, nor access to assembling technology $G^{i}, i=1,2$. The latter implies that final assembly remains at home. ${ }^{8}$ According to (2), the production of output $X^{i}$ is subject to the production function

$$
X^{i}=G^{i}\left(G_{i}^{1}\left(K_{i}^{\gamma}, L_{i}^{\gamma}\right), G_{i}^{*}\left(K_{i}^{*}, L_{i}^{*}\right)\right)
$$

if firms totally substitute fragment $G_{i}^{2}$ by the imported intermediate good $G_{i}^{*}{ }^{9} K_{i}^{*}$ and $L_{i}^{*}$ denote foreign factors. Be aware that (5) allows for the possibility that the foreign country uses a technology different from $G_{i}^{2}(\cdot)$ in the production of fragment $G_{i}^{*}$. Let

$$
\begin{aligned}
& c_{i}^{\gamma}\left(w_{K}, w_{L}, c_{i}^{*}\right) \equiv w_{K} k_{i}^{\gamma}\left(w_{K}, w_{L}, c_{i}^{*}\right) \\
+ & w_{L} l_{i}^{\gamma}\left(w_{K}, w_{L}, c_{i}^{*}\right)+c_{i}^{*} g_{i}^{*}\left(w_{K}, w_{L}, c_{i}^{*}\right)
\end{aligned}
$$

be the minimal unit cost function of outsourcing firms in sector $i$. Thereby, $c_{i}^{*}$ are

\footnotetext{
${ }^{8}$ Compare for a similar assumption Kohler (2001a).

${ }^{9}$ For simplicity, I assume that individual firms do not simultaneously use $G_{i}^{g 2}$ and $G_{i}^{*}$ in the (fragmented) production of commodity $X^{i}$. Compare (2) and (5).
} 
the costs of an imported unit of intermediate good $G_{i}^{*} \cdot c_{i}^{*}$ depends on given foreign factor prices and any trade costs. $k_{i}^{\gamma} \equiv K_{i}^{\gamma} / X^{i}, l_{i}^{\gamma} \equiv L_{i}^{\gamma} / X^{i}$ and $g_{i}^{*} \equiv G_{i}^{*} / X^{i}$ are the cost-minimal input coefficients for outsourcing firms active in sector $i$.

\section{Factor Intensities}

Optimal intensities of (home-supplied) primary factors used in the integrated and fragmented production mode of sector $i=1,2$ are given by

$$
\begin{gathered}
\phi_{i}^{f}\left(w_{K}, w_{L}\right) \equiv \frac{k_{i}^{f}\left(w_{K}, w_{L}\right)}{l_{i}^{f}\left(w_{K}, w_{L}\right)} \text { and } \\
\phi_{i}^{g}\left(w_{K}, w_{L}\right) \equiv \frac{k_{i}^{g}\left(w_{K}, w_{L}\right)}{l_{i}^{g}\left(w_{K}, w_{L}\right)}
\end{gathered}
$$

respectively, according to (3) and (4). Moreover, under international outsourcing, we obtain

$$
\phi_{i}^{\gamma}\left(w_{K}, w_{L}\right) \equiv \frac{k_{i}^{\gamma}\left(w_{K}, w_{L}, c_{i}^{*}\right)}{l_{i}^{\gamma}\left(w_{K}, w_{L}, c_{i}^{*}\right)}
$$

according to (6). Note that $\phi_{i}^{\gamma}(\cdot)$ is independent of $c_{i}^{*}$, which is a direct consequence of the separability of $G^{i}(\cdot)$. In the following, I assume that the single crossing condition of unit isocost curves in the $\left(w_{K}, w_{L}\right)$-space holds, thereby refraining from any factor intensity reversals of primary inputs. Formally, this assumption can be characterized in the following way. Let

$$
K=\left\{\phi_{1}^{f}(\cdot), \phi_{2}^{f}(\cdot), \phi_{1}^{g}(\cdot), \phi_{2}^{g}(\cdot), \phi_{1}^{\gamma}(\cdot), \phi_{2}^{\gamma}(\cdot)\right\}
$$

be the set of optimal factor intensities of primary inputs in sectors I and II for the different production modes, according (7)-(9). No factor intensity reversal means that for any pair $\kappa(\cdot) \neq \kappa^{\prime}(\cdot) \in K$ the following property holds: If $\kappa\left(w_{K}, w_{L}\right) \gtrless$ $\kappa^{\prime}\left(w_{K}, w_{L}\right)$, for some $w_{K}, w_{L}$ then $\kappa\left(w_{K}^{\prime}, w_{L}^{\prime}\right) \gtrless \kappa^{\prime}\left(w_{K}^{\prime}, w_{L}^{\prime}\right)$ for all other $w_{K}^{\prime}, w_{L}^{\prime}$. In words the ranking of different modes of production according to their factor intensities is independent of changes in $w_{K}$ and $w_{L}$.

\section{Equilibria}

\section{A. The Non-Outsourcing Equilibrium}

Define for any given $\left(w_{K}, w_{L}\right)$ 


$$
c_{1}^{a}\left(w_{K}, w_{L}\right) \equiv \min \left\{c_{i}^{1}\left(w_{K}, w_{L}\right), c_{i}^{g}\left(w_{K}, w_{L}\right)\right\}
$$

Then, factor prices in a diversified non-outsourcing equilibrium $w_{K}^{a}$ and $w_{L}^{a}$ are determined by the zero profit conditions

$$
\begin{gathered}
c_{1}^{a}\left(w_{K}, w_{L}\right)=p^{1} \text { and } \\
c_{2}^{a}\left(w_{K}, w_{L}\right)=p^{2} .
\end{gathered}
$$

Factor markets have to be cleared in equilibrium, i.e. $\Sigma_{i}\left(K_{i}^{f}+K_{i}^{g}\right)=\bar{K}$ and $\Sigma_{i}\left(L_{i}^{f}+L_{i}^{g}\right)=\bar{L}$, where $K_{i}^{g}=K_{i}^{g 1}+K_{i}^{g 2}$ and $L_{i}^{g}=L_{i}^{g 1}+L_{i}^{g 2}$ denote total employment of $K$ and $L$ in the fragmented production of sector $i$. Thereby, $K_{i}^{g}=0$ and $L_{i}^{g}=0$ if $c_{i}^{f}\left(w_{K}^{a}, w_{L}^{a}\right)<c_{i}^{g}\left(w_{K}^{a}, w_{L}^{a}\right)$ and equivalently $K_{i}^{f}=0$ and $L_{i}^{f}=0$ if ${ }_{-i}^{f}\left(\left(w_{K}^{a}, w_{L}^{a}\right)>c_{i}^{g}\left(w_{K}^{a}, w_{L}^{a}\right)\right)$. The full employment conditions determine equilibrium outputs. To make the analysis more tractable, from now on I assume $c_{i}^{f}\left(w_{K}^{a}, w_{L}^{a}\right) \neq c_{i}^{g}\left(w_{K}^{a}, w_{L}^{a}\right)$. Then, in the non-outsourcing equilibrium sector I is said to be the $K$-intensive one if $\phi_{1}^{a}\left(w_{K}, w_{L}\right)>\phi_{2}^{a}\left(w_{K}, w_{L}\right)$, with $\phi_{i}^{a}, i=1,2$ being defined as

$$
\phi_{i}^{a}\left(w_{K}, w_{L}\right) \equiv\left\{\begin{array}{lll}
\phi_{i}^{f}\left(w_{K}, w_{L}\right) & \text { if } & c_{i}^{a}\left(w_{K}^{a}, w_{L}^{a}\right)=c_{i}^{f}\left(w_{K}^{a}, w_{L}^{a}\right) \\
\phi_{i}^{g}\left(w_{K}, w_{L}\right) & \text { if } & c_{i}^{a}\left(w_{K}^{a}, w_{L}^{a}\right)=c_{i}^{g}\left(w_{K}^{a}, w_{L}^{a}\right),
\end{array}\right.
$$

Figure 1. The non-outsouring equilibrium

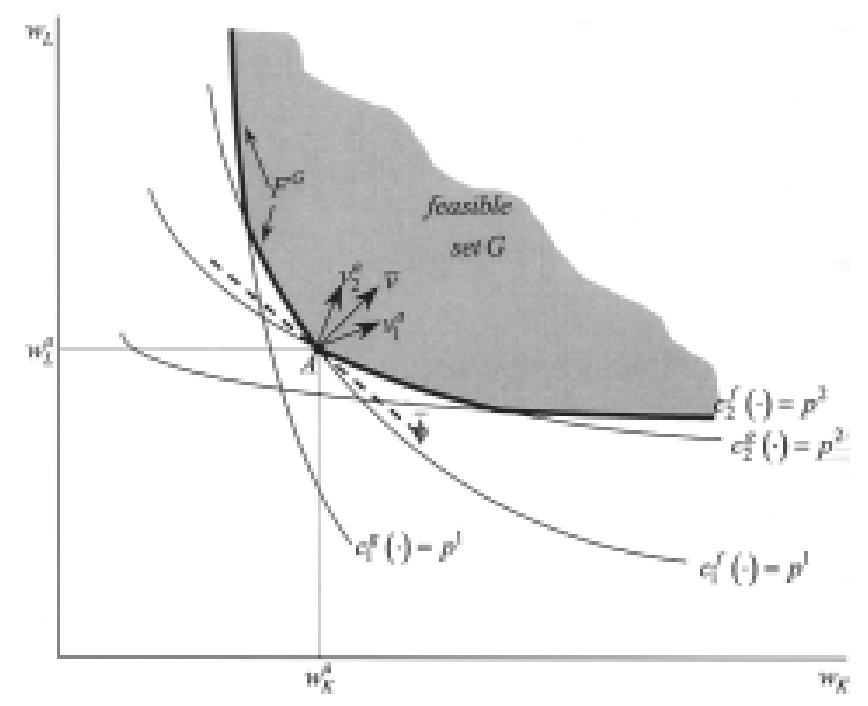


according to (7), (8) and (10). ${ }^{10}$

The non-outsourcing equilibrium is represented by figure 1 , where sector $\mathrm{I}$ is assumed to be the $K$-intensive one. ${ }^{11}$ In figure 1 set $G$ describes the feasible set and set $F^{G}$ its lower frontier, which contains all possible equilibrium combinations. ${ }^{12}$ Note that, according to figure 1 , set $G$ contains all combinations of factor prices that satisfy the constraints $c_{i}^{a}(\cdot) \geq p^{i}, i=1,2$. A formal characterization of feasible set $G$ and frontier $F^{G}$ is given in the appendix.

Now, consider point $A$ in figure 1. $v_{i}^{a}$ denotes the vector which is at factor prices $w_{K}^{a}, w_{L}^{a}$ perpendicular to the unit cost contour $c_{i}^{a}\left(w_{K}, w_{L}\right)=p^{i}, i=1,2$. Moreover, $\bar{v}$ is the vector which is in point $A$ perpendicular to line $\bar{\phi}$, which indicates the relative factor endowment of home. Then, a diversified equilibrium is reached if $\bar{v}$ lies within the cone determined by $v_{1}^{a}$ and $v_{2}^{a}$ (factor market clearing condition).

It is apparent from figure 1 that the output pattern is determined by commodity prices, the production technologies and the factor endowments of the economy. To see this, remember that all possible equilibrium factor price combinations are elements of frontier $F^{G}$. Then, according to figure 1, the economy could be completely specialized on integrated production in sector I if it were more $K$ abundant, so that the steeper line $\bar{\phi}$ would be tangent to frontier $F^{G}$ at a point above $A$.

\section{B. The Outsourcing Equilibrium}

If factor prices are not equalized by final goods trade, a decline in trade costs for intermediate goods ${ }^{13}$, i.e. a decline in $c_{i}^{*}$, may imply an incentive for firms to exploit international factor price differences by outsourcing part of the value added chain to abroad. Thus, firms in sector $i$ have at given non-outsourcing equilibrium factor prices $w_{K}^{a}, w_{L}^{a}$ economical access to international outsourcing if $c_{i}^{\gamma}\left(w_{K}^{a}, w_{L}^{a}, c_{i}^{*}\right) \leq$ $c_{i}^{a}\left(w_{K}^{a}, w_{L}^{a}\right)$, according to (3), (4), (6) and (10). Moreover, firms in sector $i$ have access to cost-saving international outsourcing if

$$
c_{i}^{\gamma}\left(w_{K}^{a}, w_{L}^{a}, c_{i}^{*}\right)<c_{i}^{a}\left(w_{K}^{a}, w_{L}^{a}\right)
$$

\footnotetext{
$\overline{{ }^{10} \text { Remember, } c_{i}^{f}\left(w_{K}^{a}, w_{L}^{a}\right)} \neq c_{i}^{g}\left(w_{K}^{a}, w_{L}^{a}\right)$ from above.

${ }^{11}$ Noteworthy, in figure 1 the ranking of technologies according to their factor intensities $\phi_{1}^{g}(\cdot)>$ $\phi_{1}^{f}(\cdot)>\phi_{2}^{g}(\cdot)>\phi_{2}^{g}(\cdot)$ is arbitrarily chosen. Sector I produces $K$-intensive in the non-outsourcing equilibrium, since $\phi_{1}^{f}\left(w_{K}^{a}, w_{L}^{a}\right)>\phi_{2}^{g}\left(w_{K}^{a}, w_{L}^{a}\right)$.

${ }^{12}$ Compare Dixit and Norman (1980) and Wong (1995) for a discussion.

${ }^{13}$ Besides declining tariffs and legal non-tariff barriers Jones (2000) and Jones and Kierzkowski (1990, 2001) point out that declining costs for service links, which are required for coordination and communication activities, are of special relevance for explaining the increase in international outsourcing.
} 
with $c_{i}^{a}\left(w_{K}^{a}, w_{L}^{a}\right)=p^{i}$, according to (11) and (12). Since it is straight forward that economical access does not change factor prices if international outsourcing is not cost-saving, i.e. if $c_{i}^{\gamma}\left(w_{K}^{a}, w_{L}^{a}, c_{i}^{*}\right)=c_{i}^{a}\left(w_{K}^{a}, w_{L}^{a}\right)$, I do ignore this case in the following analysis.

Let $\beta^{i}, i=1,2$, be implicitly defined by

$$
c_{i}^{\gamma}\left(\beta^{i}{ }^{a} w_{K}, \beta^{i} w_{L}^{a}, c_{i}^{*}\right)=c_{i}^{a}\left(w_{K}^{a}, w_{L}^{a}\right) .
$$

Then, according to (14), a cost-saving effect of international outsourcing in sector $i$ at non-outsourcing equilibrium factor prices $w_{K}^{a}, w_{L}^{a}$, arises if and only if $\beta^{i}>1$. Firms in both sectors have at given $w_{K}^{a}, w_{L}^{a}$, simultaneously access to costsaving international outsourcing, if $\beta>1$, with $\beta \equiv \min \left(\beta^{1}, \beta^{2}\right)$. Finally, the costsaving effect is higher in sector I if $\beta^{1}>\beta^{2}$ and it is more pronounced in sector II if $\beta^{1}<\beta^{2}$. With respect to its impact on factor intensities, international outsourcing is said to substitute factor $L$, if $\phi_{i}^{\gamma}\left(w_{K}^{a}, w_{L}^{a}, c_{L}^{*}\right)>\phi_{i}^{a}\left(w_{K}^{a}, w_{L}^{a}\right)$ and to substitute factor $K$ if $\phi_{i}^{\gamma}\left(w_{K}^{a}, w_{L}^{a}\right)>\phi_{i}^{a}\left(w_{K}^{a}, w_{L}^{a}\right)$. Finally, international outsourcing is neutral if $\phi_{i}^{\gamma}\left(w_{K}^{a}, w_{L}^{a}\right)=\phi_{i}^{a}\left(w_{K}^{a}, w_{L}^{a}\right)$. Compare the definition of $\phi_{i}^{a}(\cdot)$ and $\phi_{i}^{\gamma}(\cdot)$, according to (7)-(9) and (13).

Define for any given $\left(w_{K}, w_{L}\right)$

$$
c_{i}^{b}\left(w_{K}, w_{L}, c_{i}^{*}\right) \equiv \min \left\{c_{i}^{a}\left(w_{K}, w_{L}\right), c_{i}^{\gamma}\left(w_{K}, w_{L}, c_{i}^{*}\right)\right\},
$$

Figure 2. An outsourcing equilibrium, with $\phi_{1}^{\gamma}(\cdot)>\bar{\phi}>\phi_{2}^{\gamma}(\cdot)$

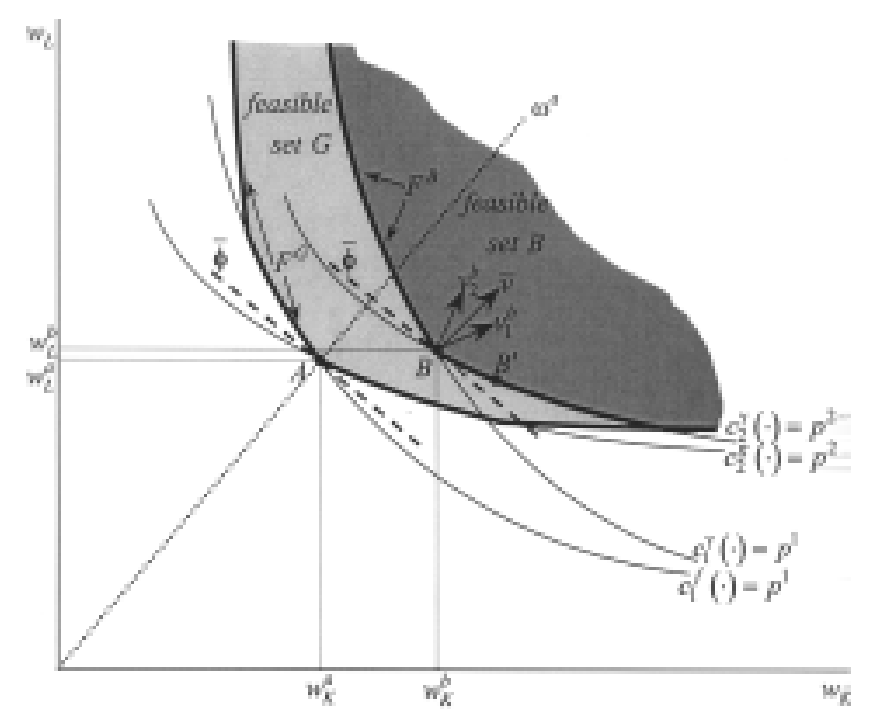


according to (6) and (10). Then, factor prices in the diversified outsourcing equilibrium $w_{K}^{b}, w_{L}^{b}$ are determined by the zero profit conditions

$$
\begin{gathered}
c_{1}^{b}\left(w_{K}, w_{L}, c_{1}^{*}\right)=p^{1} \text { and } \\
c_{2}^{b}\left(w_{K}, w_{L}, c_{2}^{*}\right)=p^{2} .
\end{gathered}
$$

Of course, factor markets have to be cleared in equilibrium. It is apparent from the discussion following figure 1 that the output pattern in the outsourcing equilibrium is determined by commodity prices $p^{i}$, the production technologies and the factor endowments of the economy. Similar to the discussion of the nonoutsourcing equilibrium it is possible to define a feasible set $B$, which contains all $\left(w_{K}, w_{L}\right)$ combinations that satisfy the constraints $c_{i}^{b}(\cdot) \geq p^{i}, i=1,2$. Then, the lower frontier $F^{B}$ of set $B$ contains all possible $\left(w_{K}, w_{L}\right)$ combinations in the outsourcing equilibrium. It is worth noting that $B \subset G$ is a direct consequence of $\beta>1$. Compare figure 2. A formal characterization of $B$ and $F^{B}$ is given in the appendix.

\section{The Distributional Effects of International Outsourcing}

To refrain from (uninteresting) border line cases, in the following I assume that $\phi_{1}^{a}\left(w_{K}, w_{L}\right) \neq \phi_{2}^{a}\left(w_{K}, w_{L}\right)$ and $\phi_{1}^{\gamma}\left(w_{K}, w_{L}\right) \neq \phi_{2}^{\gamma}\left(w_{K}, w_{L}\right)$. Then, the impact of international outsourcing on relative factor returns can be summarized in the following way.

Theorem 1. Assume that economical access to international outsourcing comprises at nonoutsourcing equilibrium factor prices $w_{K}^{a}, w_{L}^{a}$ a cost-saving effect in both sectors. Then, under diversification the following holds:

(i) If both sectors are engaged in international outsourcing and the cost-saving effect of outsourcing is highest in sector $i$, the relative return increases in favor of the factor intensively used in sector i in the outsourcing equilibrium.

(ii) If only one sector employs the outsourcing technology in equilibrium, the relative return increases in favor of the factor intensively used in the outsourcing sector.

Proof. See the appendix.

Figure 2 represents a situation where international outsourcing decreases costs in the $K$-intensive production of sector I relative to the costs of $L$-intensive production in sector II. Outsourcing substitutes factor $L$ in both sectors, i.e. $\phi_{1}^{\gamma}(\cdot)>\phi_{1}^{a}(\cdot)$ and $\phi_{2}^{\gamma}(\cdot)>\phi_{2}^{a}(\cdot)$. 
It is obvious from figure 2 that the relative cost saving effect of international outsourcing at non-outsourcing equilibrium factor prices $w_{K}^{a}, w_{L}^{a}$ is neutral, i.e. $\beta_{1}=\beta_{2}>1$, if the intersection point of the two unit isocost curves associated with international outsourcing lies on the dotted $\omega^{a}$-line in figure 2 , where $\omega^{a} \equiv w_{K}^{a} / w_{L}^{a}$ is used. But, if the cost-saving effect in sector I is higher than the cost-saving effect in sector II, i.e. if $\beta_{1}>\beta_{2}>1$, the unit isocost curve of sector 1 shifts more than that of sector II yielding an intersection point below the $\omega^{a}$-line in the case of $\phi_{1}^{\gamma}(\cdot)>\phi_{2}^{\gamma}(\cdot)$. This is drawn in figure 2. Moreover, be aware that the economy will end up on $F^{B}$ (the lower frontier of feasible set $B$ ) in the outsourcing equilibrium. Formally, $\left(w_{K}^{b}, w_{L}^{b}\right) \in F^{B}$. Then, for a given frontier $F^{B}$, the outsourc-ing equilibrium is determined by the relative endowment of the economy. Since vector $\bar{v}$, which is in point $B$ perpendicular to the line indicating the relative factor endowment of the economy $\bar{\phi}$, lies within the cone determined by $v_{1}^{b}$ and $v_{2}^{b}$, point $B$ describes the outsourcing equilibrium. ${ }^{14}$ (In point $B$ both sectors make use of the outsourcing technologies only.) The output pattern in the outsourcing equilibrium is (as in the non-outsourcing equilibrium) determined by commodity prices, the production technologies and the factor endowments of the economy. In the outsourcing equilibrium the economy could be completely specialized on the out-

Figure 3. An outsourcing equilibrium, with $\phi_{1}^{\gamma}(\cdot)<\bar{\phi}<\phi_{2}^{\gamma}(\cdot)$

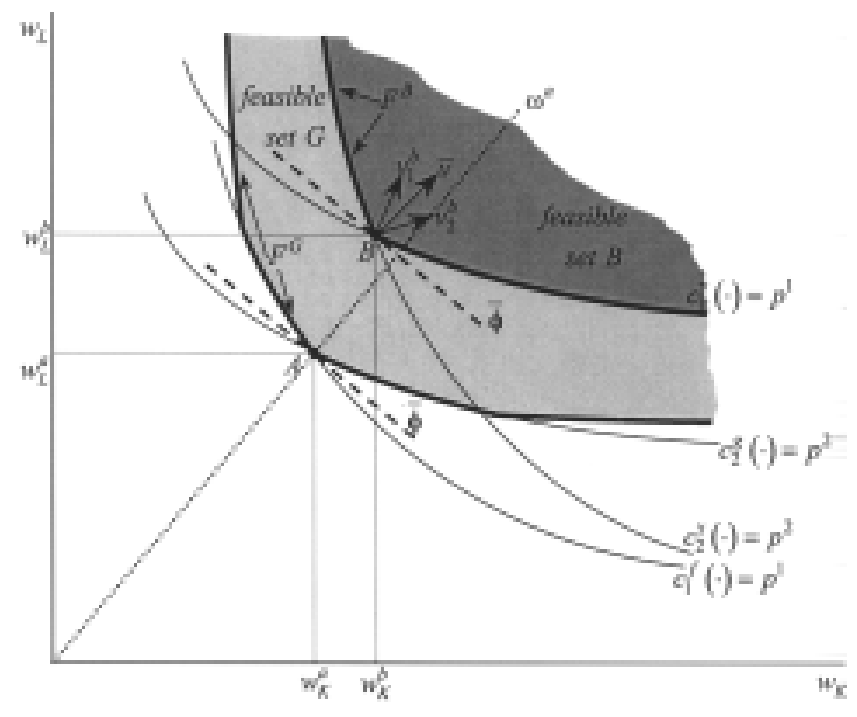

${ }^{14} v_{i_{b}}^{b}$ denotes the vector which is at factor prices $w_{K}^{b}, w_{L}^{b}$ perpendicular to frontier
$c_{i}^{b}\left(w_{K}, w_{L}, c_{i}^{*}\right)=p^{i}, i=1,2$. 
Figure 4. An outsourcing equilibrium, with $\phi_{1}^{\gamma}(\cdot)>\bar{\phi}>\phi_{2}^{g}(\cdot)$

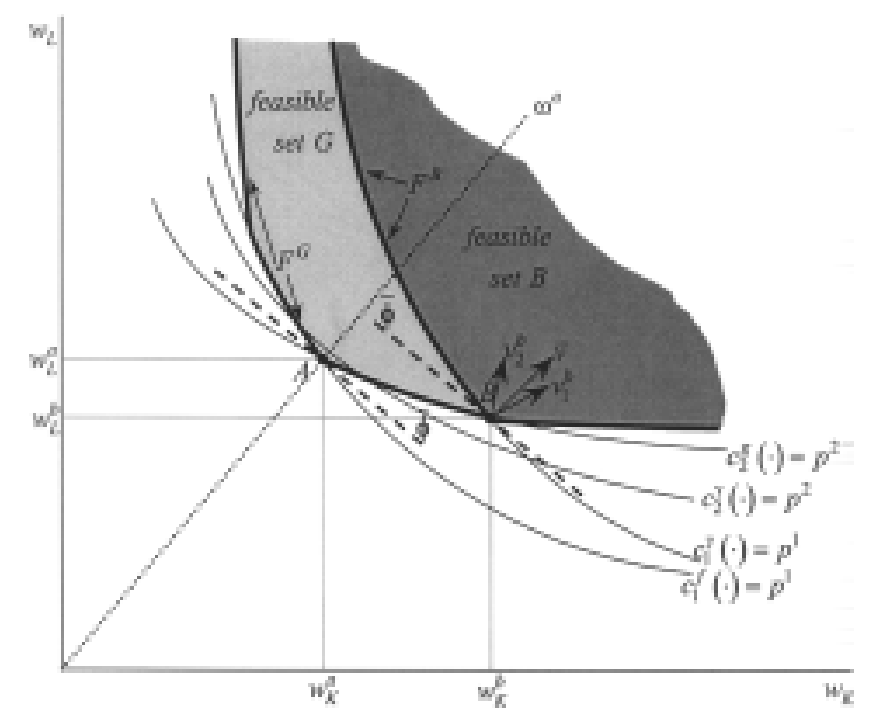

sourcing production in sector I if the economy were more $K$-abundant, so that the steeper line $\bar{\phi}$ would be tangent to frontier $F^{B}$ at a above point $B$. However, the economy could as well be specialized on the outsourcing technology in sector II, if the outsourcing technology in sector II were more $K$-intensive, so that line $\bar{\phi}$ would be tangent to $F^{B}$ at a point below point $B$. This immediately shows that the factor contents of the outsourced components matter for the output pattern of the economy.

However, according to figure 2, one may think that at least under diversification it is solely the sector bias which matters for international outsourcing. But, this conclusion is not valid. In figure 3 both sectors make use of international outsourcing in equilibrium. Moreover, $\phi_{1}^{a}\left(w_{K}, w_{L}\right)>\phi_{2}^{a}\left(w_{K}, w_{L}\right)$ and $\phi_{1}^{\gamma}\left(w_{K}, w_{L}\right)<$ $\phi_{2}^{\gamma}\left(w_{K}, w_{L}\right)$ hold, so that the ranking of sectors according to their factor intensities is affected by international outsourcing. ${ }^{15}$

Although it is again the $K$-intensive sector $\mathrm{I}$ in which at non-outsourcing equilibrium factor prices $w_{K}^{a}, w_{L}^{a}$ the cost-saving effect of international outsourcing is most pronounced, it is factor $L$ which gains relative to factor $K$ from access to international outsourcing. The reason is that although the production in sector I is $K$-intensive in the non-outsourcing equilibrium it turns out to be $L$-intensive in the outsourcing equilibrium. It is the ranking of sectors according to their factor

\footnotetext{
${ }^{15}$ Note that in figure 3 outsourcing substitutes factor $K$ in sector I and factor $L$ sector II.
} 
Figure 5. An outsourcing equilibrium, with $\beta_{1}>\beta_{2}$ and $\phi_{2}^{\gamma}(\cdot)>\bar{\phi}>\phi_{1}^{g}(\cdot)$

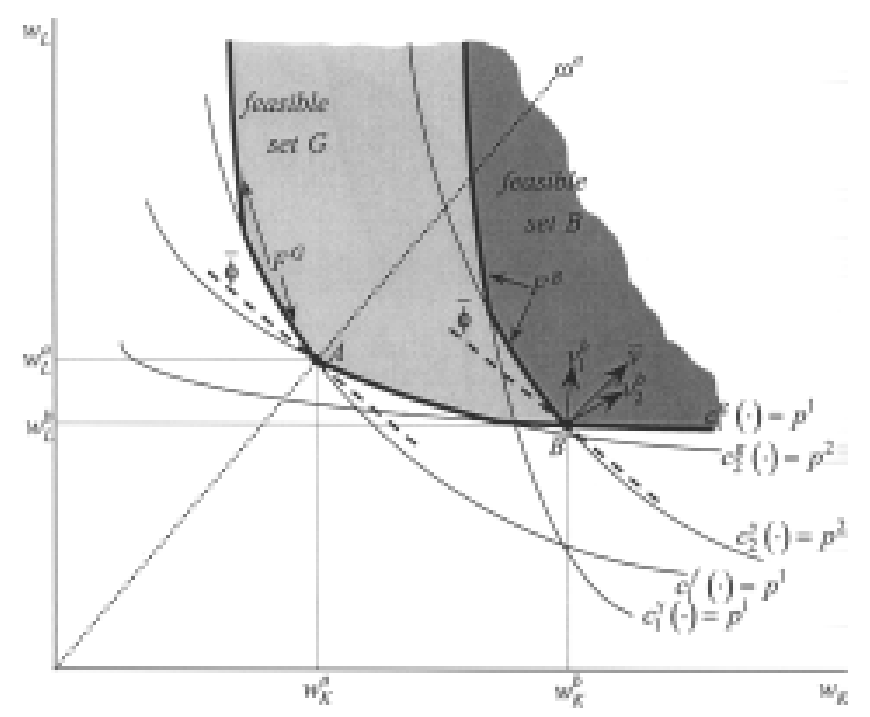

intensities in the outsourcing (and not in the non-outsourcing) equilibrium which matters for the distributional effects of international outsourcing. Thus, the factor contents of the outsourced components are relevant for the distributional effects of international outsourcing.

Due to the cost-saving effect, i.e. $\beta>1$, it is apparent that at least one sector is engaged in international outsourcing in the outsourcing equilibrium. However, non-outsourcing technologies are not necessarily substituted by outsourcing techniques in both sectors in equilibrium. Figure 4 draws a case in which sector II does not make use of international outsourcing in the outsourcing equilibrium despite the cost-saving effect of international outsourcing in sector II at non-outsourcing equilibrium factor prices $w_{K}^{a}, w_{L}^{a}$.

Finally, in figures 2-4 it is the factor intensively used in sector I (in the outsourcing equilibrium) that gains relative to the other factor and it is sector I in which the cost-saving effect of international outsourcing at non-outsourcing equilibrium factor prices is highest.

This is not necessarily the case if only one sector makes use of the outsourcing technology in equilibrium. To see this consider figure 5 where outsourcing substitutes factor $L$ in both sectors and the cost-saving effect of inter-national outsourcing is highest in sector I. However, it is only the production of sector II which makes use of international outsourcing in equilibrium, whereas in sector I both intermediate inputs of the fragmented production are produced in home. 
Since sector II turns out to be the $K$-intensive one in the outsourcing equilibrium, i.e. $\phi_{2}^{\gamma}\left(w_{K}^{b}, w_{L}^{b}\right)>\phi_{1}^{g}\left(w_{K}^{b}, w_{L}^{b}\right)$, it is factor $K$ which gains relative to factor $L$ from the cost-saving access to international outsourcing.

\section{Can Outsourcing have a Pareto-improving Impact on Factor Prices?}

So far the analysis has focused on the question of how cost-saving access to international outsourcing affects relative factor rewards. This section confronts the issue of international outsourcing with the Pareto-criterion. The main findings are summarized in theorem 2 .

Theorem 2. Assume that economical access to international outsourcing comprises at nonoutsourcing equilibrium factor prices $w_{K}^{a}, w_{L}^{a}$ a cost-saving effect in both sectors. Then, under diversification (i) at least one factor gains and (ii) a Pareto-improvement may arise.

Proof. See the appendix.

Corollary 1. A Pareto-improvement of international outsourcing is only possible if outsourcing technologies totally substitute the integrated and fragmented production mode, as described by (1) and (2), in equilibrium.

Proof. Directly follows from the properties of frontier $F^{G}$.

Part $(i)$ of theorem 2 is a direct consequence of the cost-saving effect of international outsourcing, i.e. of $\beta>1$. Since international outsourcing means that resources are more efficiently allocated, there is a potential for a Paretoimprovement in the sense that winners are able to compensate losers via lump-sum transfers. Thus, at least one factor gains from international outsourcing.

Moreover, a Pareto-improving impact of international outsourcing (without redistributional measures) may arise. Consider first that all firms in both sectors are engaged in international outsourcing in equilibrium, i.e. technologies $f$ and $g$ are totally substituted by the outsourcing production mode. In figures 2 and 3 both factors gain from an access to cost-saving international outsourcing. However, it is clear from figure 2 that a Pareto-improving factor price effect can only arise if the cost-saving effect of international outsourcing in the two sectors is not too different. ${ }^{16}$ If the cost-saving effect of international outsourcing in sector $\mathrm{I}$ is such

\footnotetext{
${ }^{16}$ It can easily be seen that the new equilibrium lies on the $\omega^{a}$-line to the right and above of point $A$ in figure 2, if the cost-saving effect is of equal size in both sectors and technologies $f$ and $g$ are totally substituted by the outsourcing production mode in the diversified outsourcing equilibrium. This guarantees a Pareto-improvement.
} 
Figure 6. An outsourcing equilibrium, with $c_{2}^{\gamma}\left(w_{K}^{a}, w_{L}^{a}, c_{2}^{*}\right)>c_{2}^{a}\left(w_{K}^{a}, w_{L}^{a}\right)=p^{2}$ and $c_{2}^{\gamma}\left(w_{K}^{b}, w_{L}^{b}\right.$ $\left.c_{2}^{*}\right)=c_{2}^{b}\left(w_{K}^{b}, w_{L}^{b}, c_{2}^{*}\right)=p^{2}$

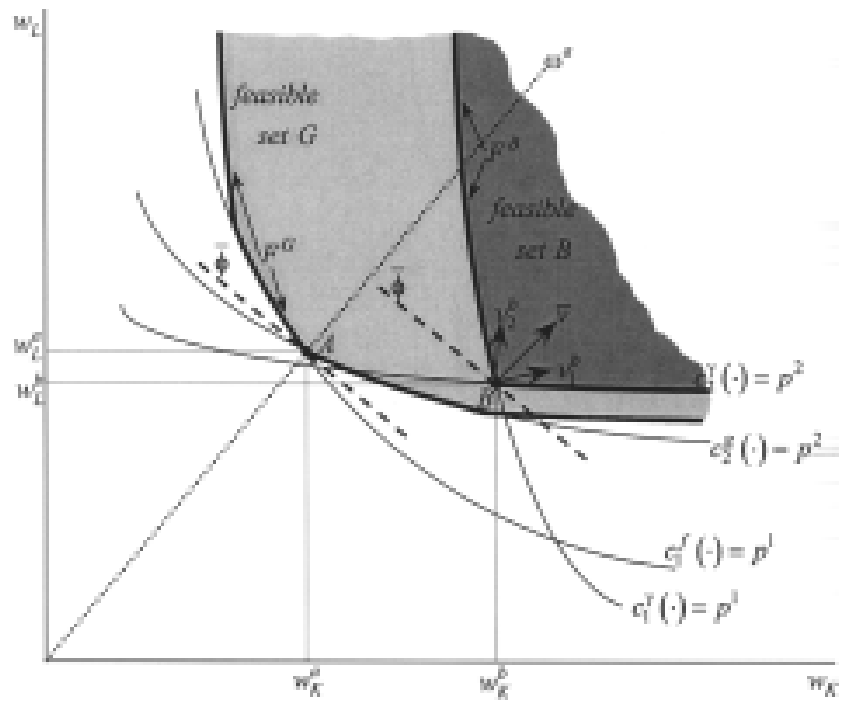

that point $B^{\prime}$ instead of $B$ describes the diversified outsourcing equilibrium in figure 2 , the return to factor $L$ declines although both sectors are engaged in international outsourcing in equilibrium.

Finally, it is apparent from figures 4 and 5 that a Pareto-improving factor price effect of international outsourcing is not possible as long as either integrated technology $f$ or fragmented technology $g$ determined by (1) or (2), respectively, survive in one sector. In figure 4 point $B$ indicates an outsourcing equilibrium in which the fragmented technology without international outsourcing survives in sector II. In equilibrium point $B w_{K}^{b}>w_{K}^{a}$ and $w_{L}^{b}<w_{L}^{a}$ hold, implying that factor $L$ loses from international outsourcing. ${ }^{17}$

\section{Extensions}

So far I have analyzed the impact of international outsourcing on factor prices if firms in both sectors have economical access to cost-saving international

\footnotetext{
${ }^{17}$ Noteworthy, the result that one factor loses if a non-outsourcing technology is in use in the outsourcing equilibrium is a direct consequence of the fact that in the $\left(w_{K}, w_{L}\right)$-space $F^{G}$ is strictly falling and convex.
} 
outsourcing at non-outsourcing equilibrium factor prices $w_{K}^{a}, w_{L}^{a}$. Thereby, it has been shown that economical access to cost-saving international outsourcing of firms in both sectors does not necessarily mean that firms in both sectors are actually engaged in outsourcing activities in equilibrium. Compare equilibrium outcome point $B$ in figure 4 . Moreover, to be used in equilibrium the outsourcing production mode has not to be cost-saving at $w_{K}^{a}, w_{L}^{a}$ in both sectors. This is shown in figure 6 , where fragmented production in the $L$-intensive sector II exhibits lower unit costs at factor prices $w_{K}^{a}, w_{L}^{a}$ than the outsourcing production mode, i.e. $c_{2}^{\gamma}\left(w_{K}^{a}, w_{L}^{a}, c_{2}^{*}\right)>c_{2}^{a}\left(w_{K}^{a}, w_{L}^{a}\right)=p^{2}$. In contrast, firms in sector I have at $w_{K}^{a}, w_{L}^{a}$ economical access to cost-saving international outsourcing since $c_{1}^{\gamma}\left(w_{K}^{a}, w_{L}^{a}, c_{1}^{*}\right)<c_{1}^{a}\left(w_{K}^{a}, w_{L}^{a}\right)=p^{1}$ holds. Then, the adjustment of factor prices induced by outsourcing in sector I may cause a cost-saving advantage of the outsourcing production mode also in sector II, so that both sectors may be engaged in outsourcing activities in equilibrium. In figure 6 factor prices in the outsourcing equilibrium are given by $w_{K}^{b}, w_{L}^{b}$ with $c_{i}^{\gamma}\left(w_{K}^{b}, w_{L}^{b}, c_{i}^{*}\right)=c_{i}^{b}\left(w_{K}^{b}, w_{L}^{b}, c_{i}^{*}\right)$ and $c_{i}^{\gamma}\left(w_{K}^{b}, w_{L}^{b}, c_{i}^{*}\right)=p^{i}$ for $i=1,2$. According to theorem 1 , the factor intensively used in sector $\mathrm{I}$ in the outsourcing equilibrium gains relative to the other factor.

However, in this case a Pareto-improvement is not possible. To see this, note that a Pareto-improvement implies $w_{K}^{b} \geq w_{K}^{a}$ and $w_{L}^{b} \geq w_{L}^{a}$ where at least one inequality holds strictly. But this cannot be an equilibrium outcome if $c_{2}^{\gamma}\left(w_{K}^{a}, w_{L}^{a}, c_{2}^{*}\right)>c_{2}^{a}\left(w_{K}^{a}, w_{L}^{a}\right)=p^{2}$ since unit isocost functions are strictly increasing in factor prices. Assuming that international outsourcing in sector II is economically attractive but not cost-saving, i.e. assuming that $c_{2}^{\gamma}\left(w_{K}^{a}, w_{L}^{a}, c_{i}^{*}\right)=$ $c_{2}^{a}\left(w_{K}^{a}, w_{L}^{a}\right)$, does not alter these results.

Finally, one may consider that only one sector has technological access to international outsourcing. This is the case most prominently discussed in the literature $^{18}$ and may be seen as special case of the more comprehensive analysis in this paper. As long as the focus lies on diversification equilibria the impact of international outsourcing on relative factor rewards is represented by part (ii) of theorem 1. According to theorem 2, a Pareto-improvement in the case of a diversified outsourcing equilibrium is not possible if only one sector has access to international outsourcing.

\footnotetext{
${ }^{18}$ Compare among others Arndt (1997, 1999), Deardorff (2001a, 2001b), Egger and Falkinger (2001), Jones and Kierzkowski (2001) and Kohler (2001a).
} 


\section{Summary}

The analysis in this paper investigates the distributional effects of international outsourcing in a two sector Heckscher-Ohlin type model. With respect to the discussion of factor-biased versus sector-biased effects of international outsourcing, it is shown that this distinction is misleading in the case of international outsourcing in both sectors. Since sectors may be differently ranked according to their factor intensities in the non-outsourcing and the outsourcing equilibrium, not only the cost-saving effects of outsourcing but also the factor contents of the outsourced fragments are relevant for the distributional effects of international outsourcing.

Concerning the Pareto-criterion the analysis in this paper shows that the more efficient allocation of resources results in a potential for a Pareto-improvement via redistributional measures of the government. However, if outsourcing arises in both sectors, it may even yield a Pareto-improvement without any policy intervention. This has so far been neglected in the literature, due to its restriction on outsourcing within one sector only.

\section{Acknowledgements}

I would like to thank Peter Egger, Josef Falkinger and an anonymous referee for their helpful comments and suggestions. The author is responsible for any errors that may remain.

Received 24 April 2001, Accepted 29 November 2001

\section{References}

Arndt, S.W. (1997), Globalization and the Open Economy, North American Journal of Economics and Finance, 8, 71-79.

Arndt, S.W. (1999), Globalization and economic development, The Journal of International Trade and Economic Development, 8, 309-318.

Deardorff, A.V. (2001a), Fragmentation in Simple Trade Models, North American Journal of Economics and Finance, 12, 121-137.

Deardorff, A.V. (2001b), Fragmentation across Cones, in S.W. Arndt and H. Kierzkowski, eds., Fragmentation: New Production Patterns in the World Economy, Oxford University Press, Oxford, 35-51.

Dixit A.K. and V. Norman (1980), Theory of International Trade, Cambridge University 
Press, Cambridge.

Egger, H. and P. Egger (2001), Cross-Border Sourcing and Outward Processing in EU Manufacturing, North American Journal of Economics and Finance 12, forthcoming.

Egger, H. and J. Falkinger (2001), Characterization of the Distributional Effects of International Outsourcing in the Hecksher-Ohlin model, CESifo Working Paper Series No. 573.

Feenstra, R.C. (1998), Integration of Trade and Disintegration of Production in the Global Economy, Journal of Economic Perspectives, 12, 31-50.

Feenstra, R.C. and G. Hanson (1996a), Globalization, Outsourcing and Wage Inequality, American Economic Review, 86, 240-245.

Feenstra, R.C. and G. Hanson (1996b), Foreign Investment, Outsourcing, and Relative Wages, in: R.C. Feenstra, G.M. Grossman., and D.A. Irwin, eds. Political Economy of Trade Policy: Essays in Honor of Jagdish Bhagwati, MIT Press, Cambridge, Mass, 89-127.

Feenstra, R.C. and G. Hanson (1997), Foreign direct investment and relative wages: Evidence from Mexicos maquiladoras, Journal of International Economics, 42, 371393.

Feenstra, R.C. and G. Hanson (1999), The Impact of Outsourcing and High-Technology Capital on Wages: Estimates for the United States, 1979-1990, Quarterly Journal of Economics, 114, 907-940.

Jones, R.W. (2000), Globalization and the Theory of Input Trade, MIT Press, Cambridge. Jones, R.W. and H. Kierzkowski (1990), The Role of Services in Production and International Trade: A Theoretical Framework, in R. Jones and A. Krueger, eds., The Political Economy of International Trade, Basil Blackwell, Oxford, 31-48.

Jones, R.W. and H. Kierzkowski (2001), A Framework of Fragmentation, in S.W. Arndt and H. Kierzkowski, eds., Fragmentation: New Production Patterns in the World Economy, Oxford University Press, Oxford, 17-34.

Kohler, W. (2001a), A Specific-Factors View on Outsourcing, North American Journal of Economics and Finance, 12, 31-53.

Kohler, W. (2001b), International Fragmenation of Value-added Chains: How Does it Affect Domestic Factor Prices?", University of Copenhagen, EPRU Working Paper Series No. 2001-03.

Krugman, P.R. (1995), Growing World Trade: Causes and Consequences, Brookings Papers on Economic Activity 1, 1995, 327-377.

Krugman, P.R. (2000), Technology, Trade and Factor Prices, Journal of International Economics 50, 51-71.

Leamer, E. (1998), In Search of Stolper-Samuelson Linkages between International Trade and Lower Wages, in: S. Collins, ed., Imports, Exports and the American Worker, Brookings, Washington, 142-202.

Mussa, M. (1979), The Two-Sector Model in Terms of its Dual: A Geometric Exposition, Journal of International Economics 9, 513-526.

Slaughter, M.J. (2000), Production transfer within multinational enterprises and American 
wages, Journal of International Economics 50, 449-472.

Wong, K.Y. (1995), International Trade in Goods and Factor Mobility, The MIT Press,

Cambridge.

\section{Appendix}

\section{A. Formal Characterization of Set $G$ and Frontier $F^{G}$}

Let $G^{i}, i=1,2$, be the upper contour set of all pairs $\left(w_{K}, w_{L}\right)$ for which $c_{i}^{a}\left(w_{K}, w_{L}\right) \geq p^{i}$ holds, according to (10)-(12). Then, $G^{1} \cap G^{2}$ defines feasible set $G$. In addition, let $F^{G^{i}}$ be the set of all pairs $\left(w_{K}, w_{L}\right)$ for which $c_{i}^{a}\left(w_{K}, w_{L}\right)=p^{i}$ holds, according to (10)-(12). Then, $F^{G^{i}}$ is the frontier set $G^{i}$ and $F^{G} \equiv G \cap$ $\left(F^{G^{1}} \cup F^{G^{2}}\right.$ ) defines the lower frontier of feasible set $G$.

\section{B. Formal Characterization of Set $B$ and Frontier $F^{B}$}

Let $B^{i}, i=1,2$, be the upper contour set of all pairs $\left(w_{K}, w_{L}\right)$ for which $c_{i}^{b}\left(w_{K}, w_{L}, c_{i}^{*}\right) \geq p^{i}$ holds, according to (16)-(18). Then, $B^{1} \cap B^{2}$ defines feasible set $B$. In addition, let $F^{B^{i}}$ be the set of all pairs $\left(w_{K}, w_{L}\right)$ for which $c_{i}^{b}\left(w_{K}, w_{L}, c_{i}^{*}\right)$ $=p^{i}$ holds, according to (16)-(18). Then, $F^{B} \equiv B \cap\left(F^{B^{1}} \cup F^{B^{2}}\right)$ is the lower frontier of feasible set $B$. Thereby, $B \subset G$ holds if $\beta>1$.

\section{Proof of Theorem 1}

Proof of part $(i)$ : Let $\left(w_{K}^{\gamma}, w_{L}^{\gamma}\right)$ be the factor prices implicitly defined by ${ }^{19}$

$$
\begin{aligned}
& c_{1}^{\gamma}\left(w_{K}, w_{L}, c_{1}^{*}\right)=p^{1} \text { and } \\
& \text { and } c_{2}^{\gamma}\left(w_{K}, w_{L}, c_{2}^{*}\right)=p^{2} .
\end{aligned}
$$

Moreover, define

$$
\begin{gathered}
R_{i}^{u} \equiv\left\{\left(w_{K}, w_{L}\right) \mid c_{i}^{\gamma}\left(w_{K}, w_{L}\right)=p^{i} \wedge w_{K} / w_{L} \geq w_{K}^{a} / w_{L}^{a}\right\} \text { as well as } \\
R_{i}^{l} \equiv\left\{\left(w_{K}, w_{L}\right) \mid c_{i}^{\gamma}\left(w_{K}, w_{L}\right)=p^{i} \wedge w_{K} / w_{L} \leq w_{K}^{a} / w_{L}^{a}\right\}
\end{gathered}
$$

for $i=1,2$. Now assume first that $\beta^{i}>\beta^{j}$, where $i \in\{1,2\}$ and $j \in\{1,2\}$ and $i \neq j$ with and remember $\beta>1$, with $\beta=\min \left(\beta_{1}, \beta_{2}\right)$. Then, the following

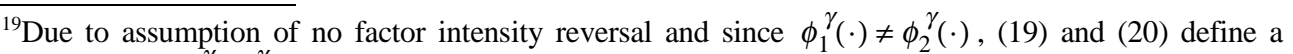
unique pair $\left(w_{K}^{\gamma}, w_{L}^{\gamma}\right)$.

${ }^{20} \mathrm{Be}$ aware that $F^{B} \cap R_{i}^{u} \neq\{\}$ is guaranteed by the definition of $F^{B}$, and the assumptions $\beta^{i}>\beta^{j}$ and $\phi_{i}^{\gamma}\left(w_{K}, w_{L}\right)>\phi_{j}^{\gamma}\left(w_{K}, w_{L}\right)$.
} 
holds: If $\phi_{i}^{\gamma}\left(w_{K}, w_{L}\right)>\phi_{j}^{\gamma}\left(w_{K}, w_{L}\right)$, then $F^{B} \cap R_{j}^{l}=\{\}$, according to the factor intensity assumptions and the definition of frontier $F^{B}$. Therefore, $w_{K}^{\gamma} / w_{L}^{\gamma} \leq$ $w_{K}^{a} / w_{L}^{a}$ cannot hold in equilibrium if both sectors make use of international outsourcing. Moreover, note that if $F^{B} \cap R_{j}^{u} \neq\{\}$, then $\left(w_{K}^{\gamma}, w_{L}^{\gamma}\right) \in F^{B} \cdot{ }^{20}$ $\left(w_{K}^{\gamma}, w_{L}^{\gamma}\right) \in F^{B}$ and $\left(w_{K}^{\gamma}, w_{L}^{\gamma}\right) \notin F^{G}$ together with $\left.\bar{\phi} \in\right] \phi_{j}^{\gamma}\left(w_{K}^{\gamma}, w_{L}^{\gamma}\right), \phi_{i}^{\gamma}\left(w_{K}^{\gamma}, w_{L}^{\gamma}\right)[$, guarantee a diver-sified equilibrium with both sectors making use of international outsourcing and relative factor prices $w_{K}^{\gamma} / w_{L}^{\gamma}>w_{K}^{a} / w_{L}^{a} \cdot{ }^{21}$ In accordance, if $\phi_{i}^{\gamma}\left(w_{K}, w_{L}\right)<\phi_{j}^{\gamma}\left(w_{K}, w_{L}\right)$, then $F^{B} \cap R_{j}^{u}=\{\}$. Therefore, $w_{K}^{\gamma} / w_{L}^{\gamma}<w_{K}^{a} / w_{L}^{a}$ must hold in a diversified equili-brium if both sectors make use of international outsourcing.

Second, if $\beta^{i}=\beta^{j}$ then $w_{K}^{\gamma} / w_{L}^{\gamma}=w_{K}^{a} / w_{L}^{a}$ and $\left(w_{K}^{\gamma}, w_{L}^{\gamma}\right) \in F^{B}$. Moreover, according to $\beta>1,\left(w_{K}^{a} / w_{L}^{a}\right) \notin F^{G}$. Then, $\left(w_{K}^{\gamma}, w_{L}^{\gamma}\right) \in F^{B}$ and $\left.\bar{\phi} \in\right] \phi_{i}^{\gamma}\left(w_{K}^{\gamma}, w_{L}^{\gamma}\right)$, $\phi_{j}^{\gamma}\left(w_{K}^{\gamma}, w_{L}^{\gamma}\right){ }^{22}$, guarantee a diversified equilibrium with both sectors making use of international outsourcing. This completes the proof of part $(i)^{23}$

Proof of part (ii): Let $w_{K}^{\eta}, w_{L}^{\eta}$ be implicitly determined by

$$
\begin{gathered}
c_{i}^{\gamma}\left(w_{K}, w_{L}, c_{i}^{*}\right)=p^{i} \text { and } \\
c_{j}^{a}\left(w_{K}, w_{L}\right)=p^{j}
\end{gathered}
$$

according to (6) and (10)-(12), where sector $j$ does not employ the outsourcing technology $\gamma^{24}$ Thereby, $i \in\{1,2\}, j \in\{1,2\}$ and $i \neq j$ are considered. Define

$$
\begin{gathered}
C_{j}^{f} \equiv F^{G} \cap\left\{\left(w_{K}, w_{L}\right) \mid c_{j}^{f}\left(w_{K}, w_{L}\right)=p^{j}\right\} \text { and } \\
C_{j}^{g} \equiv F^{G} \cap\left\{\left(w_{K}, w_{L}\right) \mid c_{j}^{g}\left(w_{K}, w_{L}\right)=p^{j}\right\} .
\end{gathered}
$$

Moreover use

$$
\phi_{j}^{\eta}\left(w_{K}, w_{L}\right)=
$$

\footnotetext{
${ }^{21}$ Of course there may also be a diversified equilibrium with both sectors making use of international outsourcing if $\left(w_{K}^{\gamma}, w_{L}^{\gamma}\right) \in F^{B}$ and $\left(w_{K}^{\gamma}, w_{L}^{\gamma}\right) \in F^{G}$. However, in this case it is not guaranteed that indeed both sectors make use of international outsourcing at factor prices $w_{K}^{\gamma}$, $w_{L}^{\gamma}$. The reason is that in one sector firms are indifferent between using one of the non-outsourcing technologies (indicated by $f$ or $g$ ) and the outsourcing production mode. However, if both sectors make use of international outsourcing in equilibrium, part (i) of theorem 1 as well as its proof are relevant.

${ }^{22} \mathrm{Be}$ aware that $\left.\bar{\phi} \in\right] \phi_{i}^{\gamma}\left(w_{K}^{\gamma}, w_{L}^{\gamma}\right), \phi_{j}^{\gamma}\left(w_{K}^{\gamma}, w_{L}^{\gamma}\right)[$ is a necessary condition for a diversified equilibrium with international outsourcing in both sectors.

${ }^{23}$ Note that if $w_{K}^{\gamma}, w_{L}^{\gamma}$ describe factor prices in the outsourcing equilibrium, then $w_{K}^{\gamma}=w_{K}^{b}$ and $w_{L}^{\gamma}=w_{L}^{b}$, according to (17) and (18).

${ }^{24}$ For a simultaneous use of a non-outsourcing and the outsourcing technology in sector $j$ compare the discussion in footnote 22 and the proof of part (i) of theorem 1. Moreover, note that if sector $j$ uses a non-outsourcing technology, sector $i$ must use the outsourcing technology in equilibrium, which is a direct consequence of $\beta>1$.
} 


$$
\left\{\begin{array}{l}
\min \left(\phi_{j}^{f}\left(w_{K}, w_{L}\right), \phi_{j}^{g}\left(w_{K}, w_{L}\right)\right) \forall\left(w_{K}, w_{L}\right) \in\left\{\left(w_{K}, w_{L}\right) \mid w_{K} / w_{L}<w_{K}^{a} / w_{L}^{a}\right\} \\
\max \left(\phi_{j}^{f}\left(w_{K}, w_{L}\right), \phi_{j}^{g}\left(w_{K}, w_{L}\right)\right) \forall\left(w_{K}, w_{L}\right) \in\left\{\left(w_{K}, w_{L}\right) \mid w_{K} / w_{L}>w_{K}^{a} / w_{L}^{a}\right\}
\end{array}\right.
$$

to define

$$
\phi^{j}\left(w_{K}, w_{L}\right) \equiv\left\{\begin{array}{l}
\phi_{j}^{f}\left(w_{K}, w_{L}\right) \forall\left(w_{K}, w_{L}\right) \in\left(C_{j}^{f} \backslash C_{j}^{g}\right) \\
\phi_{j}^{g}\left(w_{K}, w_{L}\right) \forall\left(w_{K}, w_{L}\right) \in\left(C_{j}^{g} \backslash C_{j}^{f}\right) \\
\phi_{j}^{h}\left(w_{K}, w_{L}\right) \forall\left(w_{K}, w_{L}\right) \in\left(C_{j}^{f} \cap C_{j}^{g}\right)
\end{array}\right.
$$

Similar to the proof of part $(i)$ we first assume that sector $i$ is the $K$-intensive one in the outsourcing equilibrium, i.e. $\phi_{i}^{\gamma}\left(w_{K}^{\eta}, w_{L}^{\eta}\right)>\bar{\phi}$. Then, if

$$
\left(C_{j}^{f} \cup C_{j}^{g}\right) \cap\left\{\left(w_{K}, w_{L}\right) \mid w_{K} / w_{L}<w_{K}^{a} / w_{L}^{a}\right\}=\{\}
$$

$\left(w_{L}^{\eta}, w_{L}^{\eta}\right) \notin F^{G} \cap\left\{\left(w_{K}, w_{L}\right) \mid w_{K} / w_{L}<w_{K}^{a} / w_{L}^{a}\right\}$ follows immediately from (25) and (26). Moreover, if

$$
\left(C_{j}^{f} \cup C_{j}^{g}\right) \cap\left\{\left(w_{K}, w_{L}\right) \mid w_{K} / w_{L}<w_{K}^{a} / w_{L}^{a}\right\} \neq\{\}
$$

then $\phi^{j}\left(w_{K}, w_{L}\right)>\bar{\phi}$ for all $\left(w_{K}, w_{L}\right) \in Z \cap\left\{\left(w_{K}, w_{L}\right) \mid w_{K} / w_{L}<w_{K}^{a} / w_{L}^{a}\right\}$, with $Z \equiv C_{j}^{f} \cup C_{j}^{g}$. This is a direct consequence of the convexity of feasible set $G$, the definition of $F^{G}$ and the assumption that minimal unit isocost curves are increasing in factor prices. Be aware that both $\phi_{i}^{\gamma}\left(w_{K}^{\eta}, w_{L}^{\eta}\right)>\bar{\phi}$ and $\phi^{j}\left(w_{K}^{\eta}, w_{L}^{\eta}\right)>\bar{\phi}$ cannot simultaneously hold in a diversified equilibrium described by (23) and (24). This proves that $\left(w_{K}^{\eta}, w_{L}^{\eta}\right) \notin F^{G} \cap\left\{\left(w_{K}, w_{L}\right) \mid w_{K} / w_{L}<w_{K}^{a} / w_{L}^{a}\right\}$ if $\phi_{i}^{\gamma}\left(w_{K}^{\eta}, w_{L}^{\eta}\right)>\bar{\phi}$.

In addition, it is obvious that if

$$
\left(C_{j}^{f} \cup C_{j}^{g}\right) \cap\left\{\left(w_{K}, w_{L}\right) \mid w_{K} / w_{L}>w_{K}^{a} / w_{L}^{a}\right\} \neq\{\}
$$

then $\phi^{j}\left(w_{K}, w_{L}\right)<\bar{\phi}$ for all $\left(w_{K}, w_{L}\right) \in Z \cap\left\{\left(w_{K}, w_{L}\right) \mid w_{K} / w_{L}>w_{K}^{a} / w_{L}^{a}\right\}$. This follows immediately from the convexity of feasible set $G$, the definition of $F^{G}$ and the assumption that minimal unit isocost curves are increasing in factor prices. Be aware that $\bar{\phi} \in] \phi^{j}\left(w_{K}^{\eta}, w_{L}^{\eta}\right), \phi_{i}^{\gamma}\left(w_{K}^{\eta}, w_{L}^{\eta}\right)$ [ must hold in a diversified equilibrium described by (23) and (24) which is the case if $\phi^{j}\left(w_{K}^{\eta}, w_{L}^{\eta}\right)<\bar{\phi}$. Then, if $\left(w_{K}^{\eta}, w_{L}^{\eta}\right) \in F^{G} \cap F^{B}$ (23) and (24) describe a diversified equilibrium with $w_{K}^{\eta} / w_{L}^{\eta}>w_{K}^{a} / w_{L}^{a}$. Finally, due to $\left(w_{K}^{\eta}, w_{L}^{\eta}\right) \in F^{G} \cap F^{B}$ and $\beta>1, w_{K}^{\eta} / w_{L}^{\eta}=w_{K}^{a} / w_{L}^{a}$, 
cannot hold in a diversified equilibrium described by (23) and (24). In the same way it can be shown that if $\phi_{i}^{\gamma}\left(w_{K}^{\eta}, w_{L}^{\eta}\right)<\bar{\phi}$, according to $\left.\bar{\phi} \in\right] \phi_{i}^{\gamma}\left(w_{K}^{\eta}, w_{L}^{\eta}\right)$, $\phi^{j}\left(w_{K}^{\eta}, w_{L}^{\eta}\right)\left[\right.$ and $\left(w_{K}^{\eta}, w_{L}^{\eta}\right) \in F^{G} \cap F^{B},(23)$ and (24) describe a diversified equilibrium with $w_{K}^{\eta} / w_{L}^{\eta}<w_{K}^{a} / w_{L}^{a}$. This concludes the proof of part (ii) of theorem

\section{1. ${ }^{25}$ D. Proof of Theorem 2}

Proof of part $(i)$ : Denote with $\left(w_{K}^{a}, w_{L}^{a}\right) \in F^{G}$ factor prices in the diversified non-outsourcing equilibrium and with $\left(w_{K}^{b}, w_{L}^{b}\right) \in F^{B}$ factor prices in the diversified outsourcing equilibrium, according to (11)-(12) and (17)-(18), respectively. Then, it is a direct consequence of the convexity of feasible set $G$, the definition of $F^{G}$ and the assumption that minimal unit isocost curves are increasing in factor prices that $w_{K}^{b}>w_{K}^{a}$ if $w_{L}^{b} \leq w_{L}^{a}$ and $w_{L}^{b}>w_{L}^{a}$ if $w_{K}^{b} \leq w_{K}^{a}$ must hold in equilibrium, since $B \subset G$, according to $\beta>1 .{ }^{26}$

Proof of part (ii): Define

$$
P \equiv\left\{\left(w_{K}, w_{L}\right) \mid \min \left[\left(w_{K}-w_{K}^{a}\right),\left(w_{L}-w_{L}^{a}\right)\right] \geq 0\right\} \backslash\left(w_{K}^{a}, w_{L}^{a}\right)
$$

as the set of factor prices $\left(w_{K}, w_{L}\right)$ which are Pareto-superior to $\left(w_{K}^{a}, w_{L}^{a}\right)$. Note that by definition $P \subset G$. Moreover, since $P \cap B \neq\{\}^{27}$, a Pareto-improving factor price impact of international outsourcing may arise.

\footnotetext{
$\overline{{ }^{25} \text { Note that if } w_{K}^{\eta}, w_{L}^{\eta}}$ describe factor prices in the outsourcing equilibrium, then $w_{K}^{\eta}=w_{K}^{b}$ and $w_{L}^{\eta}=w_{L}^{b}$, according to (17) and (18).

${ }^{26}$ Remember that $\beta=\min \left(\beta^{1}, \beta^{2}\right)$.

${ }^{27}$ Define for $\tilde{\beta}=\max \left(\beta^{1}, \beta^{2}\right)$, with $\beta^{2}>1$ and $\beta^{2}>1, w_{K}^{\beta} \equiv \tilde{\beta} w_{K}^{a}$ and $w_{K}^{\beta} \equiv \tilde{\beta} w_{L}^{a}$. Then, $\left(w_{K}^{\beta}, w_{L}^{\beta}\right) \in F^{B}$ follows, according to the definition of $F^{B}$. Moreover, $\left(w_{K}^{\beta}, w_{L}^{\beta}\right) \in P$ holds, according to (28). This immediately shows that $P \cap B \neq\{\}$.
} 